\title{
Analisis Persepsi Mahasiswa Terhadap Penggunaan Kahoot Sebagai Media Evaluasi Pembelajaran Pada Mata Kuliah Teori Ekonomi Moneter
}

\author{
Yhadi Firdiansyah $^{1 *}$, Heni Purwa Pamungkas ${ }^{2}$ \\ ${ }^{1}$ Universitas Islam Negeri Maulana Malik Ibrahim Malang \\ ${ }^{2}$ Universitas Negeri Surabaya \\ ${ }^{1}$ Email: yhadi_firdiansyah@uin-malang.ac.id ; ${ }^{2}$ Email: henipamungkas@unesa.ac.id \\ *Corresponding Author
}

(Received: 31 Oktober 2020; Accepted: 15 Desember 2020; Published: 10 Januari 2020)

\begin{abstract}
This study aims to analyze students' perceptions about the Kahoot application as a learning evaluation medium. The approach to this research is descriptive quantitative research with data collection techniques using a questionnaire. The population in this study were students of the 5th semester of the Social Studies education program who took the Monetary Economic Theory course involving 83 students. The results showed that the use of Kahoot as a learning evaluation media received a positive response from students. This is because Kahoot is easy to use, has an attractive appearance, and is transparent in displaying scores. Thus, students are increasingly motivated to learn in order to achieve the highest score.
\end{abstract}

Keywords: Kahoot; Motivation; Learning Evaluation Media

\begin{abstract}
Abstrak. Penelitian ini bertujuan untuk menganalisis persepsi mahasiswa mengenai aplikasi Kahoot sebagai media evaluasi pembelajaran. Pendekatan pada penelitian ini adalah penelitian kuantitatif deskriptif dengan teknik pengumpulan data menggunakan kuesioner. Populasi dalam penelitian ini adalah mahasiswa prodi pendidikan IPS semester 5 yang mengikuti mata kuliah Teori Ekonomi Moneter dengan melibatkan 83 mahasiswa. Hasil penelitian menunjukkan bahwa penggunaan Kahoot sebagai media evaluasi pembelajaran mendapatkan respon yang positif dari mahasiswa. Hal ini disebabkan karena Kahoot mudah digunakan, memiliki tampilan yang menarik, serta transparan dalam menampilkan skor. Sehingga, mahasiswa semakin termotivasi untuk belajar agar meraih skor tertinggi
\end{abstract}

Kata Kunci: Kahoot; Motivasi; Media Evaluasi Pembelajaran

\section{PENDAHULUAN}

Pendidikan merupakan bagian yang sangat penting dalam meningkatkan kualitas sumber daya manusia di suatu negara, termasuk Indonesia. Oleh karena itu pendidikan harus senantiasa ditingkatkan baik dari sisi kualitas maupun kuantitasnya, terlebih di era revolusi industri 4.0 sektor pendidikan menuntut adanya perubahan yang mengarah pada kemajuan dalam penggunaan teknologi. Salah satu bentuk pengaruh kemajuan pada sektor pendidikan di era industri 4.0 adalah perubahan perilaku interaksi antara guru dan siswa, dimana semula pembelajaran harus dilakukan dengan face to face atau bertatap muka dikelas namun kali ini harus mengalami perubahan yakni dengan berkolaborasi memanfaatkan jaringan internet (Online Learning). Dengan demikian, dibutuhkan kesiapan guru sebagai sumber daya pendidik yang memiliki kemampuan untuk merespon perkembangan ilmu pengetahuan dan teknologi melalui penguasaan model, metode dan media pembelajaran untuk diaplikasikan dalam proses pembelajaran dikelas (Ramli et al., 2018).

Kehadiran teknologi menjadikan penggunaan permainan tradisional didalam kelas semakin berkurang karena dengan teknologi dapat menciptakan permainan yang lebih menarik sesuai dengan gaya hidup peserta didik. Teknologi permainan online atau digital dalam proses pembelajaran lebih relevan karena salah satu manfaat dari permainan digital adalah merangsang pembelajaran. Pembelajaran akan berlangsung efektif dan menyenangkan sebagai jalan lahirnya generasi yang berkualitas sebaimana yang dicita citakan dalam tujuan Pendidikan (Rahmatullah, Inanna, Rakib, et al., 2020). 
Siswa dapat merasakan elemen konfrontasi, merasakan pencapaian atau kehilangan, dan menerima umpan balik instan (Kapp, 2012). Selain itu menurut (Iwanmoto \& Darren, 2017) pembelajaran berbasis permainan memiliki potensi untuk menjadi alat pembelajaran yang efektif karena merangsang komponen visual dan verbal. Untuk itu, media pembelajaran perlu didesain dengan menarik sehingga efektif digunakan (Rahmatullah, Inanna, \& Ampa, 2020).

Saat ini banyak perusahaan layanan internet yang memberikan fasilitas untuk menunjang pembelajaran didalam kelas yang terhubung dengan jaringan internet sebagai sarana kolaborator untuk menyatukan kegiatan tatap muka dengan jaringan internet, dan salah satu yang sering digunakan dalam pembelajaran yaitu Kahoot. Media pembelajaran game-based learning Kahoot mampu memberikan pengalaman pembelajaran dengan meningkatkan keikutsertaan kolaborasi peserta didik dalam pembelajaran. Digital Game Based Learning merupakan metode penggabungan konten pendidikan kedalam game dengan tujuan melibatkan peserta didik. Penggunaan software game di komputer maupun aplikasi pada smartphone didesain untuk menyeimbangkan konten pembelajaran dengan konten permainan serta mampu menilai kemampuan pembelajaran apakah sudah menguasai dan mampu mengaplikasikan pengetahuaanya pada dunia nyata (Muhammad Ervan, 2017).

Aplikasi Kahoot sebagai platform teknologi pembelajaran mengkombinasikan pengalaman evaluasi pembelajaran dengan mengkombinasikan melalui game interaktif dan dilengkapi sistem monitoring aktifitas para peserta didik (Correia \& Santos, 2017). Inovasi Platform Kahoot ini mampu membantu aktifitas evaluasi pembelajaran menjadi menarik, interaktif, kondusif dan mudah dalam memonitaring hasil belajar (Kurnia Dewi, 2018).

Keberhasilan seorang siswa setelah melakukan proses pembelajaran dapat dilihat dari prestasi hasil belajarnya. Prestasi mempunyai fungsi yang sangat penting dalam dunia pendidikan. Pada dasarnya prestasi belajar merupakan cerminan dari hasil usaha dan kemampuan yang dilakukan seorang siswa dalam proses belajar mengajar.

Selain mempengaruhi proses pembelajaran dan pemahaman, permainan digital berkaitan dengan kondisi mental dan sosial (Lee $\&$ Hammer, 2011). Ketika motivasi siswa untuk belajar meningkat, mereka akan cenderung untuk datang ke kelas. Konsep ini didukung oleh Dörnyei \& Ushioda (2011) yang menemukan bahwa motivasi berkaitan erat dengan partisipasi. Selain itu, game digital dapat menciptakan lingkungan belajar yang baik dan mendorong keterlibatan pengguna (Goehle, 2013). Menurut Reeve (2012), keterlibatan mengacu pada sejauh mana seorang peserta didik menunjukkan partisipasi dinamis, perhatian, antusiasme ketika dia terlibat dalam proses pembelajaran, yang dapat berkontribusi pada kinerja pembelajaran yang memuaskan.

Penelitian terkait implementasi Kahoot sebagai media evaluasi sudah banyak digunakan untuk pembelajaran sains dan bahasa, namun implementasi pada bidang sosial terutama pembelajaran Ekonomi masih belum banyak dilakukan. Sehingga diperlukan penelitian yang mengkaji tentang penerapan Kahoot pada pembelajaran di bidang Ekonomi. Adapun beberapa penelitian penerapan Kahoot dalam bidang bahasa diantaranya yaitu penelitian yang dilakukan oleh (Yürük, 2019), (Median\&Hurtado, 2019), (Hadijah, et.al, 2020), dan (Wichadee \& Pattanapichet, 2018). Hasil penelitian yang dilakukan oleh (Yürük, 2019) menyatakan bahwa Kahoot dapat mendorong rasa ingin tahu peserta didik, ketertarikan dalam mempelajari materi, serta persaingan yang menyenangkan. Lebih lanjut, Kahoot juga dapat mendorong peserta didik menjadi lebih aktif dalam proses pembelajaran. Hasil penelitian tersebut sejalan dengan penelitian yang dilakukan oleh (Hadijah, et.al, 2020) dan (Medina \& Hurtado, 2017) yang mengemukakan bahwa Kahoot dapat dijadikan alternative bagi guru untuk mengajarkan kosakata baru pada pembelajaran Bahasa Inggris dan memberikan kegiatan belajar yang menyenangkan bagi siswa.

Sedangkan penelitian terkait penerapan Kahoot pada bidang sains dilakukan oleh (Prieto, et.al., 2019), (Jones, et.al., 2019), dan (Cameron \& Bizo, 2019). Hasil penelitian tersebut menyatakan bahwa Kahoot dapat manjadi salah satu alat bantu pengajar dalam menciptakan pembelajaran yang menyenangkan, kompetitif, dan berkesan.

\section{METODE PENELITIAN}

Penelitian ini merupakan penelitian yang menggunakan pendekatan penelitian kuantitatif deskriptif, dimana tujuan penelitian ini adalah untuk menganalisis persepsi mahasiswa mengenai aplikasi Kahoot sebagai media evaluasi 
pembelajaran. Untuk mengetahui persepsi mahasiswa, berikut ini adalah rumusan masalah yang diteliti:

1. Apakah penggunaan Kahoot dapat meningkatkan motivasi belajar mahasiswa?

2. Apakah Kahoot efektif digunakan dalam proses pembelajaran?

3. Apakah Kahoot dapat meningkatkan pengetahuan mahasiswa?

Instrumen penelitian terdiri dari kuesioner dengan pertanyaan tertutup dan pertanyaan terbuka. Terdapat 20 item pernyataan dengan menggunakan 5 skala Likert. Angka 1 merepresentasikan "sangat tidak setuju", angka 2 merepresentasikan "tidak setuju", angka 3 merepresentasikan " kurang setuju", angka 4 merepresentasikan "Setuju", dan angka 5 merepresentasikan "sangat setuju". Mahasiswa memilih angka 1 apabila pernyataan tersebut sangat tidak sesuai dengan pendapatnya dan memilih angka 5 apabila bunyi pernyataan tersebut sangat sesuai dengan pendapatnya.

Penyusunan item pernyataan didasarkan pada tiga aspek, yaitu: motivasi, keefektifan, dan pengetahuan. Pada aspek motivasi, terdiri dari 9 indikator. Aspek keefektifan terdiri dari 7 indikator, dan aspek pengetahuan terdiri dari 4 indikator. Agar mendapatkan hasil yang lebih komprehensif, di bagian akhir kuesioner disertakan pertanyaan dengan opsi jawaban terbuka. Sehingga, mahasiswa lebih leluasa dalam menyampaikan pandangannya terkait penggunaan Kahoot sebagai media evaluasi pembelajaran.

\section{HASIL DAN PEMBAHASAN}

\begin{tabular}{|c|c|c|c|c|c|}
\hline Item & $\begin{array}{l}\text { STS } \\
(\%)\end{array}$ & $\begin{array}{c}\text { TS } \\
(\%) \\
\end{array}$ & $\begin{array}{l}\text { KS } \\
(\%)\end{array}$ & $\begin{array}{c}\mathrm{S} \\
(\%)\end{array}$ & $\begin{array}{l}\text { SS } \\
(\%)\end{array}$ \\
\hline $\begin{array}{l}\text { Saya tertantang untuk menganalisis soal secara cepat sehingga } \\
\text { dapat menjawab lebih dahulu dari rekan lainnya }\end{array}$ & 0 & 1.2 & 12 & 59 & 26.8 \\
\hline $\begin{array}{l}\text { Evaluasi pembelajaran dengan media kahoot meningkatkan jiwa } \\
\text { kompetititf saya agar bersaing secara sehat dengan rekan lainnya }\end{array}$ & 1.2 & 1.2 & 6 & 77.3 & 14.4 \\
\hline Media kahoot memotivasi saya untuk belajar lebih giat & 0 & 1.2 & 9.6 & 59 & 30.2 \\
\hline $\begin{array}{l}\text { Saya bersemangat menyelesaikan soal evaluasi dengan media } \\
\text { kahoot }\end{array}$ & 0 & 2.4 & 12 & 64 & 21.6 \\
\hline $\begin{array}{l}\text { Sistem penilaian dengan menggunakan media kahoot memotivasi } \\
\text { saya untuk mendapatkan nilai tertinggi (top scorer) }\end{array}$ & 1.2 & 0 & 4.8 & 80.7 & 13.3 \\
\hline Media kahoot meningkatkan motivasi belajar saya & 0 & 2.4 & 7.2 & 61.4 & 30 \\
\hline Media kahoot meningkatkan minat belajar saya & 2.4 & 2.4 & 9.6 & 71 & 14.6 \\
\hline Saya termotivasi untuk berpartisipasi aktif dalam tim & 0 & 1.2 & 3.6 & 61.4 & 33.8 \\
\hline
\end{tabular}
kuesioner dengan pertanyaan tertutup dan pertanyaan terbuka, populasi dalam penelitian ini adalah mahasiswa prodi pendidikan IPS di UIN Maulana Malik Ibrahim Malang pada semester 5 yang mengikuti mata kuliah Teori Ekonomi Moneter dengan melibatkan 83 mahasiswa, dimana sebanyak 28 orang berjenis kelamin lakilaki dan 55 orang berjenis kelamin perempuan.

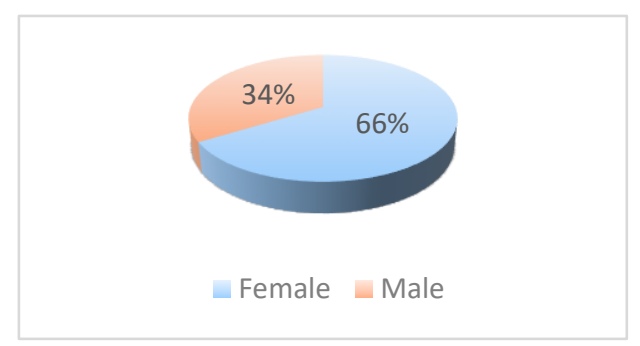

Grafik 1. Proporsi responden berdasarkan jenis kelamin

Penelitian ini melibatkan 83 mahasiswa yang mengambil mata kuliah Teori Ekonomi Moneter. Dari 83 mahasiswa, proporsi mahasiswa perempuan sebanyak $66 \%$ atau 55 orang dan proporsi mahasiswa laki-laki sebesar $34 \%$ atau 28 orang.

\section{Apakah penggunaan Kahoot dapat meningkatkan motivasi belajar mahasiswa?}

Untuk mengetahui persepsi mahasiswa terkait peningkatan motivasi belajar dengan menggunakan Kahoot, ada beberapa item pertanyaan yang diajukan. Berikut ini adalah tabel rekapitulasi perhitungan skala Likert dari masing-masing item pertanyaan:

Tabel 1. Frekuensi respon mahasiswa terkait aspek motivasi 


\begin{tabular}{|l|l|l|l|l|}
\hline 0 & 1.2 & 4.8 & 59 & 35 \\
\hline
\end{tabular}

Keterangan: STS = sangat tidak setuju; TS = tidak setuju; KS = kurang setuju; $S=$ setuju; $\mathrm{SS}=$ sangat setuju

Dari tabel 1 diatas, diketahui bahwa sebagian besar partisipan menyatakan setuju bahwa penggunaan Kahoot meningkatkan motivasi belajar. Hal ini tercermin pada item pernyataan "media Kahoot memotivasi saya untuk belajar lebih giat", sekitar 98,8\% partisipan menyatakan setuju dengan pernyataan tersebut. Hal ini dikarenakan mahasiswa berambisi untuk mendapatkan nilai tertinggi, mendorong mahasiswa untuk mempelajari terlebih dahulu materi perkuliahan sehingga saat diadakan kuis dengan menggunakan media Kahoot mereka dapat menjawab pertanyaan yang diajukan dengan benar. Lebih lanjut, tampilan Kahoot yang fleksibel dan memungkinkan untuk menampilkan skor mahasiswa menjadi daya Tarik tersendiri bagi mahasiswa, karena mereka merasa lebih bersemangat saaat memperoleh nilai tertinggi. Hasil penelitian ini senada dengan penelitian yang dilakukan (Lin et. all, 2018) yang menyatakan bahwa penggunaan Kahoot dalam proses belajar dapat membantu mahasiswa meningkatkan pengetahuan serta motivasi belajarnya. Media Kahoot menjadikan kegiatan asesmen atau kuis lebih menarik bagi mahasiswa (Omar, 2017). Tampilan Kahoot yang menarik, menjadi faktor yang dapat meningkatkan minat dan keingintahuan mahasiswa. Temuan penelitian ini juga mendukung hasil penelitian yang dilakukan oleh (Muhridza, et.al, 2018) yang menyatakan bahwa Kahoot ditemukan memotivasi siswa untuk lebih perhatian dan menjadi lebih terlibat dalam partisipasi kelas. Hal ini senada dengan hasil penelitian dari (Bicen \& Kocakoyun, 2018) yang menyatakan bahwa penerapan gamification method pada proses pembelajaran di kelas meningkatkan minat mahasiswa dan ambisi untuk sukses.

\section{Apakah Kahoot efektif digunakan dalam proses pembelajaran?}

Untuk mengetahui persepsi mahasiswa terkait keefektifan penggunaan Kahoot sebagai media evaluasi, ada 7 aspek pernyataan yang tertuang dalam kuesioner. Berikut ini adalah sebaran frekuensi respon partisipan pada masingmasing item pernyataan.

Tabel 2. Frekuensi persepsi responden terhadap keefektifan media Kahoot

\begin{tabular}{|l|c|c|c|c|c|}
\hline Item & $\begin{array}{c}\text { STS } \\
(\mathbf{\%})\end{array}$ & $\begin{array}{c}\text { TS } \\
(\mathbf{\%})\end{array}$ & $\begin{array}{c}\text { KS } \\
(\mathbf{\%})\end{array}$ & $\begin{array}{c}\text { S } \\
(\mathbf{\%})\end{array}$ & $\begin{array}{c}\text { SS } \\
(\mathbf{\%})\end{array}$ \\
\hline $\begin{array}{l}\text { Saya dapat memahami instruksi dari dosen terkait } \\
\text { penggunaan media evaluasi kahoot }\end{array}$ & 2.4 & 2.4 & 8.4 & 76 & 10.8 \\
\hline $\begin{array}{l}\text { Pertanyaan yang tersedia sangat bervariasi dan } \\
\text { tidak membosankan }\end{array}$ & 2.4 & 2.4 & 7.2 & 78.3 & 9.7 \\
\hline $\begin{array}{l}\text { Pembelajaran menjadi lebih menyenangkan dengan } \\
\text { menggunakan media Kahoot dan tidak monoton }\end{array}$ & 2.4 & 2.4 & 9.6 & 71 & 14.6 \\
\hline $\begin{array}{l}\text { Penggunaan media Kahoot sudah efektif dan tidak } \\
\text { membuang-buang waktu }\end{array}$ & 2.4 & 2.4 & 3.6 & 68.6 & 23 \\
\hline Waktu pengerjaan soal memadai & 0 & 1.2 & 3.6 & 66.2 & 29 \\
\hline $\begin{array}{l}\text { Dengan media kahoot meningkatkan kemampuan } \\
\text { untuk bekerja sama dalam kelompok (team work) }\end{array}$ & 0 & 1.2 & 12 & 59 & 27.8 \\
\hline $\begin{array}{l}\text { Pertanyaan yang diberikan sesuai dengan topik } \\
\text { perkuliahan }\end{array}$ & 0 & 1.2 & 10.8 & 53 & 35 \\
\hline
\end{tabular}

Keterangan: STS = sangat tidak setuju; TS = tidak setuju; KS = kurang setuju; $S=$ setuju; $S S=$ sangat setuju

Aspek keefektifan media Kahoot dapat dilihat dari faktor alokasi waktu, instruksi yang jelas, variasi tipe soal, serta kesesuaian antara pertanyaan dengan materi perkuliahan. Dari tabel 2 diatas, diketahui bahwa $95.2 \%$ partisipan menyatakan bahwa penggunaan Kahoot telah efektif. Namun, ada $4.8 \%$ yang menyatakan bahwa penggunaan Kahoot belum efektif. Hal ini disebabkan karena alokasi waktu yang terbatas dan jaringan internet yang tidak stabil. Meski 
secara keseluruhan penggunaan Kahoot dinyatakan efektif, namun Kahoot juga memiliki keterbatasan pada alokasi waktu yang cukup singkat dan sangat bergantung pada jaringan internet. Ketidakstabilan koneksi internet menghambat respon mahasiswa dalam menjawab pertanyaan yang muncul. Temuan ini mendukung hasil penelitian dari (Nguyen\&Yukawa, 2019) yang menyatakan bahwa keberagaman tingkat koneksi internet menjadi salah satu kelemahan dari penggunaan Kahoot. Meski kendala koneksi internet menjadi salah satu kekurangan dari penggunaan Kahoot, namun secara keseluruhan responden menyatakan bahwa Kahoot efektif digunakan sebagai media evaluasi.

\section{Apakah Kahoot dapat meningkatkan pengetahuan mahasiswa?}

Terdapat 4 item pernyataan untuk mengetahui lebih lanjut persepsi mahasiswa terkait penggunaan media Kahoot dalam membantu mahasiswa dalam meningkatkan pengetahuaannya. Berikut ini adalah sebaran frekuensi jawaban mahasiswa untuk masingmasing item pernyataan.

Tabel 3. Persepsi mahasiswa mengenai penggunaan Kahoot dalam meningkatkan pengetahuan.

\begin{tabular}{|l|c|c|c|c|c|}
\hline \multicolumn{1}{|c|}{ Item } & $\begin{array}{c}\text { STS } \\
(\boldsymbol{\%})\end{array}$ & $\begin{array}{c}\text { TS } \\
(\mathbf{\%})\end{array}$ & $\begin{array}{c}\text { KS } \\
(\boldsymbol{\%})\end{array}$ & $\begin{array}{c}\text { S } \\
(\boldsymbol{\%})\end{array}$ & $\begin{array}{c}\text { SS } \\
(\boldsymbol{\%})\end{array}$ \\
\hline $\begin{array}{l}\text { Pertanyaan yang disajikan mengasah keterampilan } \\
\text { memecahkan masalah }\end{array}$ & 3.6 & 3.6 & 12 & 70 & 10.8 \\
\hline $\begin{array}{l}\text { Dapat menambah pengetahuan saya terhadap materi } \\
\text { perkuliahan }\end{array}$ & 1.2 & 1.2 & 20.6 & 61.4 & 15.6 \\
\hline $\begin{array}{l}\text { Penggunaan media evaluasi kahoot mambantu sayaa } \\
\text { mengingat kembali materi perkuliahan yang telah } \\
\text { dipelajari }\end{array}$ & 1.2 & 3.6 & 20.6 & 57.8 & 16.8 \\
\hline $\begin{array}{l}\text { Evaluasi dengan menggunakan media kahoot } \\
\text { membantu saya dalam mengasah kemampuan berfikir } \\
\text { kritis }\end{array}$ & 0 & 1.2 & 12 & 63.8 & 23 \\
\hline
\end{tabular}

Keterangan: STS = sangat tidak setuju; TS = tidak setuju; KS = kurang setuju; $S=$ setuju; $S S=$ sangat setuju

Dari tabel 3 diatas, diketahui bahwa 95.2\% partisipan menyatakan bahwa media Kahoot membantu dalam meengingat kembali (reinforcement) materi perkuliahan yang telah dipelajari. Lebih lanjut, evaluasi pembelajaran yang dikemas dengan menggunakan media Kahoot membantu mahasiswa untuk berfikir kritis.

Secara keseluruhan, sebagian besar mahasiswa memberikan respon yang positif terkait penggunaan Kahoot sebagai media evaluasi di akhir pembelajaran. Kecepatan serta ketepatan jawaban akan sangat mempengaruhi

\section{KESIMPULAN DAN SARAN}

Hasil penelitian ini menyimpulkan bahwa penggunaan Kahoot sebagai media evaluasi pembelajaran mendapatkan respon yang positif dari mahasiswa. Hal ini disebabkan karena Kahoot mudah digunakan, memiliki tampilan yang menarik, serta transparan dalam skor yang diperoleh mahasiswa. Diakhir permainan, maka akan terlihat siapa yang mendapatkan skor tertinggi. Hal ini memicu motivasi mahasiswa untuk belajar lebih giat agar meraih skor tertinggi. Temuan ini mendukung penelitian yang dilakukan oleh (Jones, et.al, 2019) bahwa media Kahoot efektif untuk meningkatkan prestasi akademik peserta didik. Selain itu, Kahoot juga menjadi media yang efektif dari segi waktu, karena proses perhitungan nilai dilakukan secara otomatis tanpa perlu menghitung ulang. Lebih lanjut, Kahoot juga dapat membantu memperkuat pemahamaan mahasiswa terkait materi yang dipelajari (Sabandar, et.al., 2018).

menampilkan skor. Sehingga, mahasiswa semakin termotivasi untuk belajar agar meraih skor tertinggi. Namun, hasil penelitian ini tidak dapat digeneralisasikan secara luas karena penggunaan Kahoot sangat tergantung dengan subjek atau materi ajar yang digunakan. Saran untuk 
penelitian selanjutnya, penggunaan Kahoot dapat diterapkan pada subjek atau mata kuliah lainnya dengan mempertimbangkan karakteristik materi ajar (learning material). Selain itu, perlu dilakukan penelitian eksperimen untuk menguji seberapa besar keefektifan Kahoot sebagai media evaluasi.

\section{DAFTAR RUJUKAN}

Bicen, Huseyin, Senay Kocakoyun. (2018). Perceptions of Students for Gamification Approach: Kahoot as a Case Study. International Journal of Emerging Technologies in Learning 13(2), 72-93

Cameron, Kristie E. \& Bizo, Lewis A. (2019). Use of the Game-Based Learning Platform KAHOOT! To Facilitate Learner Engagement in Animal Science Students. Research in Learning Technology, 27, 1-14

Dewi, KC. 2018. Pengembangan alat evaluasi menggunakan Aplikasi Kahoot pada pembelajaran Matematika Kelas $X$. Diunduh dari http://repository.radenintan.ac.id/ 4286/1/Skripsi Cahya Kurnia.pdf

Dörnyei, Z., \& Ushioda, E. (2011). Teaching and Researching Motivation (2nd ed.). Harlow: Pearson Education.

Ervan, Muhammad. 2017. Meningkatkan Minat dan Hasil Belajar mahasiswa pada Perkuliahan Elektronika Dasar Melalui Digital Game Base Learning. Prosiding Seminar Nasional Pendidikan dan Pengembangan Pendidikan Indonesia. ISSN 2598-1978

Goehle, G. (2013). Gamification and webbased homework. PRIMUS: Problems, Resources, and Issues in Mathematics Undergraduate Studies, 23(3), 234-246.

Hadijah, et.al. (2020). Interactive Game "Kahoot!" as the Media of Students' Vocabulary Assessment. Journal on English as a Foreign Language, 10(1), 84-102

Iwamoto, Dr. Darren H., et al. (2017). "Analyzing The Of The Testing Effect Using Kahoot On Student Performance." Tutkish Online Journal of Distance Education 18, no. 2

Jones, Serena M., et.al. (2019). A 'KAHOOT!' Approach: The Effectiveness of GameBased Learning for an Advanced Placement Biology Class. Simulation \& Gaming, 50(6), 832-847
Kapp, K. M. (2012). The Gamification of Learning and Instruction. San Francisco: Wiley.

Lee, J. J., \& Hammer, J. (2011). Gamification in education: what, how, why bother? Definitions and uses. Exchange Organizational Behavior Teaching Journal, 15(2), 1-5. Retrieved 18 October 2016 from https://www.uwstout.edu/soe/profdev/re sources/upload/Lee-Hammer-AEQ2011.pdf.

Lin, Debbita Tan Ai, et. all. (2018). Kahoot! It: Gamification in Higher Education. Pertanika Journal Social Sciences \& Humanities 26(1), 565-582

M. Correia and R. Santos,2017. "Game-Based Learning:The Use of Kahoot in teacher education". 2017 International Symposium on Komputer in Education (SIIE), Lisbon, 2017,pp. 1-4, doi: 10.1109/SIIE.2017.8259670

Median, Edison G Llerena\&Hurtado, Carlos P. Rodriguez. (2017). Kahoot! A Digital Tool for Learning Vocabulary in A Language Classroom. Revista Publicando, 14(1), 441-449

Muhridza, Nur Hazwani Mohd, et. al. (2018). Using Game-Based Technology, KAHOOT! For Classroom Engagement. LSP International Journal, 5(2), 37-48

Nguyen, Thuy Thi Thanh \& Yukawa Takashi. (2019). Kahoot with Smartphones in Testing and Asessment of Language Teaching and Learning, the Need of Training on Mobile Devices for Vietnamese Teachers and Students. International Journal of Information and Education Technology, 9(4), 286-296

Omar, Nurul Nisa. (2017). The Effectiveness of Kahoot Application Towards Students' Good Feedback Practice. PEOPLE: International Journal of Social Sciences, 3(2), 2551-2562

Prieto, Marta Curto, et.al. (2019). Student Assessment of the Use of Kahoot in the Learning Process of Science and Matemathics. Education Sciences, 9, 113

Rahmatullah, R., Inanna, I., \& Ampa, A. T. (2020). Media Pembelajaran Audio Visual Berbasis Aplikasi Canva. Jurnal Pendidikan Ekonomi Undiksha, 12(2), 317-327.

Rahmatullah, R., Inanna, I., Rakib, M., Mustari, 
M., \& Rabania. (2020). Developing

Tematic Economic Comic with Characters for Early Childhood. EST Journal of

Educational Science and Technology, 6(3), 293-300.

Ramli, A., Rahmatullah, R., Inanna, I., \& Dangnga, T. (2018). Peran Media Dalam Meningkatkan Efektivitas Belajar. Lembaga Pengabdian Kepada Masyarakat Universitas Negeri Makassar, 5-7.

Reeve, J. (2012). A self-determination theory perspective on student engagement. In S. L. Christenson, A. L. Reschly, \& C. Wylie (Eds.), Handbook of Research on Student Engagement (pp. 149-172). New York: Springer.
Sabandar, Grace Nathania Clara, et.al. (2018). Kahoot!: Bring the Fun Into the Classroom!. Indonesian Journal of Informaticss Education. 2(2), 127-134

Wichadee, Saovapa, \& Pattanapichet Fasawang. (2018). Enhancement of Performance and Motivation Through Application of Digital Games in an English Language Class, 18(1), 77-92

Yürük, N. (2019). Edutainment: Using Kahoot! As A Review Activity in Foreign Language Classrooms. Journal of Educational Technology \& Online Learning, 2(2), 89-101 